\title{
Influence of cloned Escherichia coli hemolysin genes, S-fimbriae and serum resistance on pathogenicity in different animal models
}

\author{
J. Hacker, ${ }^{1 *}$ H. Hof, ${ }^{2}$ L. Emödy ${ }^{3}$ and W. Goebel ${ }^{1}$ \\ 1/nstitut füt Genetik und Mikrobiologie, University of Würzburg, Röntgenring 11 , \\ D-8700 Würzburg, F.R.G.; ${ }^{2}$ Institut für Hygiene und Mikrobiologie, University of Würzburg, \\ J.-Schneider-Str. 2, D.8700 Würzburg, F.R.G.; ${ }^{3}$ Institute of Microbiology, University of Pecs, \\ Szigeti ut. 12, Hungary
}

(Received November 25, 1985; accepted in revised form April 7, 1986)

Hacker, J. (Institut für Genetik und Mikrobiologie, University of Würzburg, D-8700 Würzburg, F.R.G.I, H. Hof, L. Emödy and W. Goebel. Influence of cloned hemolysin genes, S-fimbriae and serum resistance on pathogenicity in different animal models. Microbial Pathogenesis 1986; 1 : 000-000.

The virulence of the uropathogenic $E$. coli strain $536(06: \mathrm{K} 15: \mathrm{H} 31)$ which produces the S-fimbrial adhesin $\left(\mathrm{Sfa}^{+}\right)$, is serum-resistant $\left(\mathrm{Sre}^{+}\right)$and hemolytic $\left(\mathrm{Hly}^{+}\right)$and its derivatives were assessed in five different animal models. Cloned hemolysin $(h / y)$ determinants from the chromosomes of 06,018 and $075 \mathrm{E}$. coli strains and from the plasmid pHly152 were introduced into the spontaneous $\mathrm{Sfa}^{-}$, Sre ${ }^{-}, \mathrm{Hly}^{-}$mutant 536-21 and its $\mathrm{Sfa}^{+}, \mathrm{Sre}^{+}, \mathrm{Hly}^{-}$variant 536-31. As already demonstrated for the 536-21 strains (Infect. Immun. 42: 57-63) the 018-hly determinant but not the plasmid-encoded hly determinant of pHly152 transformed into 536-31 contribute to lethality in a mouse peritonitis model. Similar results were obtained with both Hly host strains and their $\mathrm{Hly}^{+}$transformants in a chicken embryo test and in a mouse nephropathogenicity assay in which the renal bacterial counts were measured 15 min to 8 hours after i.v. infection. S-fimbriae and serum resistance had only a marginal influence in these three in vivo systems. In contrast all three factors, S-fimbriae, serum resistance and hemolysin, were necessary for full virulence in a respiratory mouse infection assay. In a subcutaneously-induced sepsis model in the mouse restoration of S-fimbriae and serum resistance and separately chromosomally-encoded hemolysis increased virulence to a level comparable to that of the parental 536 strain.

Key words: E. coli hemolysin. S-fimbriae; serum resistance. E. coli virulence; animal models; gene cloning.

\section{Introduction}

Escherichia coli strains are responsible for most urinary tract infections (UTI). Certain E. coli clones cause neonatal sepsis and meningitis. ${ }^{1-3}$ Many cell components such as adhesins, serum resistance factors, cytolysins and others have been shown to be associated with extraintestinal virulence in $E$. coli. ${ }^{4}$

Adhesion factors which recognize galactosyl-galactose receptors ( $P$ fimbriae ${ }^{2.5}$ ) are common among UTI strains. S-fimbriae specifically bind to sialic acid containing structures are frequently associated with isolates from cases of newborn meningitis. ${ }^{3,6}$ The genetic determinants for S-fimbrial adhesins (sfa) cover a stretch of

\footnotetext{
"Author to whom correspondence should be addressed.
} 


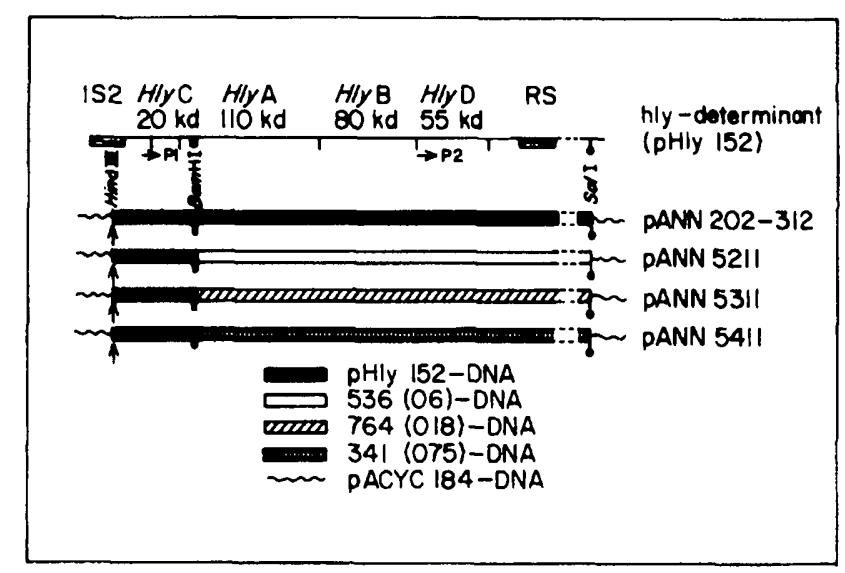

Fig. 1. Physical maps of the different cloned hly determinants used in this study.

DNA of $6.5 \mathrm{~kb}$ and are highly conserved among UTI and meningitis isolates /ref. 7 and Ott et al., submitted for publication. Certain $\mathrm{O}$ - and $\mathrm{K}$-antigens including $\mathrm{K}^{18}$ and other components of the outer membrane cause resistance of the strains to serum (Sre) and phagocytosis (ref. 9 and Hughes et al., submitted for publication).

Hemolytic $\left(\mathrm{Hly}^{+}\right) \mathrm{E}$. coli strains have very often been found among UTI isolates. ${ }^{1,2,10}$ The hemolysin determinants $(h / y)$ are usually located on the chromosome of these strains. ${ }^{10-12}$ Plasmid encoded $h l y$ determinants are very rare among uropathogenic $E$. coli. ${ }^{10.12}$ The chromosomal and plasmid encoded hemolysin determinants share high sequence homology and they both consist of at least four genes involved in the synthesis of the active hemolysin (hlyA, hlyC) and its transport (h/yB, hlyD;12-14 see Fig. 1). Two promoter regions have been identified. One promoter $(\mathrm{P} 1)$ is located upstream of $h l y C$ regulating the transcription of $h l y C, A, B$; hlyD seems to be transcribed from the other promoter (P2). It has been shown that the flanking regions of the plasmid-encoded hly determinants include an IS2 sequence at the left side and another IS-like element (RS) on the right side.15,16 Very recently the entire nucleotide sequence of one chromosomally encoded ${ }^{17}$ and one plasmid encoded $h l y$ determinant ${ }^{17}$ a were described.

It has been suggested for a while that hemolysin contributes to pathogenicity of $E$. coli11,18-22 in most cases, however, data from such studies have been obtained with clinical isolates or genetic variants of strains which have been mutagenized or have lost or received large plasmids or parts of the chromosome. The use of recombinant DNA techniques, i.e. cloning of hly determinants, their introduction into suitable host strains and in vivo tests with these genetically manipulated bacteria offered new possibilities to confirm these studies. Thus, in two animal models the direct contribution of $E$. coli hemolysin to virulence has been established. ${ }^{23-25}$

One has to point out, nevertheless, that extraintestinal $E$. coli infections and in particular those of the kidneys (pyelonephritis) are severe, sometimes chronic, inflammatory processes. ${ }^{26}$ It is hard if not impossible to simulate such an infection in a single artificial animal model. Thus, we decided to compare the animal reactions to the same genetically defined strains in several different in vivo test systems. In this paper we first present direct evidence that cloned $E$. coli hemolysin is the main virulence factor in a chicken embryo assay and in a mouse nephropathogenicity test. In a mouse respiratory infection model and in a mouse sepsis system the hemolysin acts in concert with S-fimbriae and a serum resistance factor. 


\section{Results}

\section{Genetic manipulation and characterization of bacterial strains}

All the strains used were derived from the wild-type isolate $E$. coli 536 . Strain 536 was isolated from a patient suffering from an urinary tract infection in Würzburg ${ }^{28}$ and was identified by standard methods. The strain belongs to the serotype 06:K15:H31 and exhibits the S-fimbrial adhesin (Sfa ${ }^{+}$) which consists of protein appendices and a mannose-resistant, neuraminidase-sensitive binding factor. ${ }^{6}$ In addition the strain is serum-resistant $\left(\mathrm{Sre}^{+}\right)$and produces hemolysin $\left(\mathrm{Hly}^{+}\right)$. The hemolytic phenotype of strain 536 results from the expression of two hemolysin determinants both of which are located on the chromosome. ${ }^{15}$

As indicated in Table 1 a spontaneous mutant, 536-21, has lost the ability to produce the S-fimbrial adhesin ( $\mathrm{Sfa}^{-}$), is sensitive to human serum (Sre ${ }^{-}$), and is nonhemolytic ( $\left.\mathrm{Hly}^{-}\right)$. The hemolysin-negative phenotype of the strain is due to deletion events which affect both hemolysin determinants. ${ }^{15.28}$ In contrast the loss of S-fimbriae formation results from a block at the level of transcription of the adhesin genes. ${ }^{29}$ The sfa determinant is most likely structurally intact and the same may be true for the determinant responsible for serum-resistance (Hughes \& Hacker, unpublished results). Both S-fimbriae and serum-resistance were regained following transformation and subsequent integration of a sfa ${ }^{+}$-cosmid into the chromosome of mutant 536-21. The mechanism which leads to the restoration of both phenotypes remains unclear. The resulting strain 536-31 $\left(\mathrm{Sfa}^{+}, \mathrm{Sre}^{+}, \mathrm{Hly}^{-}\right)$, was used together with the Sfa- ${ }^{-} \mathrm{Sre}^{-}, \mathrm{Hly}^{-}$mutant 536-21 as a recipient for the introduction of different cloned hemolysin determinants.

The hemolysin determinants tested were cloned and subcloned from the large transferable plasmid pHly $152^{13,30}$ and from the chromosomes of the $E$. coli strains 536 (see above), $764\left(018: \mathrm{K}^{2}: \mathrm{H}^{-}\right.$) and $341\left(075: \mathrm{K} 95: \mathrm{H}^{+} ; 31\right)$. As indicated in Fig. 1 the four recombinant $h / y^{+}$DNAs vary in the $h / y A, h / y B$ and $h / y D$ genes of the hemolysin determinants. They all were introduced into the mutant strain 536-21. Two of them (pANN202-312-pHly152 and pANN5311-018) were additionally transformed into the strain 536-31 (see Table 1). Thus, two sets of isogenic strains were constructed which only differ in hemolysin production. The strains 536-21 and 536-31 differ in the presence or absence of S-fimbriae and serum resistance. All these strains were used for in vivo tests.

Table 1 Bacterial strains used

\begin{tabular}{|c|c|c|}
\hline Strains & $\begin{array}{l}\text { Virulence determinants, } \\
\text { Antibiotic markers }\end{array}$ & Reference \\
\hline $\begin{array}{l}536 \\
536-21 \\
536-31 \\
536-21 \text { pANN202-312 } \\
536-21 \text { pANN5211-06 } \\
536-21 \text { pANN5311-018 } \\
536-21 \text { pANN5411-075 } \\
536-31 \text { pANN202-312 } \\
536-31 \text { pANN5311-018 }\end{array}$ & 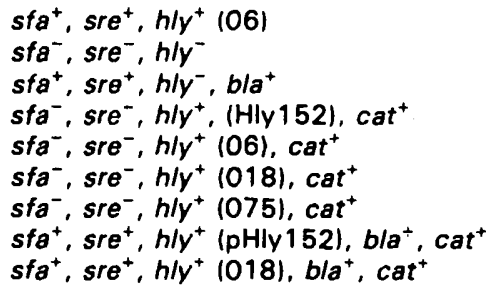 & $\begin{array}{c}28 \\
28 \\
\text { this study } \\
24 \\
24 \\
24 \\
24 \\
\text { this study } \\
\text { this study }\end{array}$ \\
\hline
\end{tabular}

All strains carry the $\mathrm{O}$-antigen $\mathrm{O} 6$ and the $\mathrm{K}$-antigen $\mathrm{K} 15$ and they are resistant to streptomycin.

'The following virulence determinants were tested: S-fimbriae antigen (sfa), serum resistance factor (sre) and hemolysin ( $h / y)$. In addition some strains were resistant to ampicillin (b/a+) or to chloramphenicol $\left(\right.$ cat $\left.^{+}\right)$. 

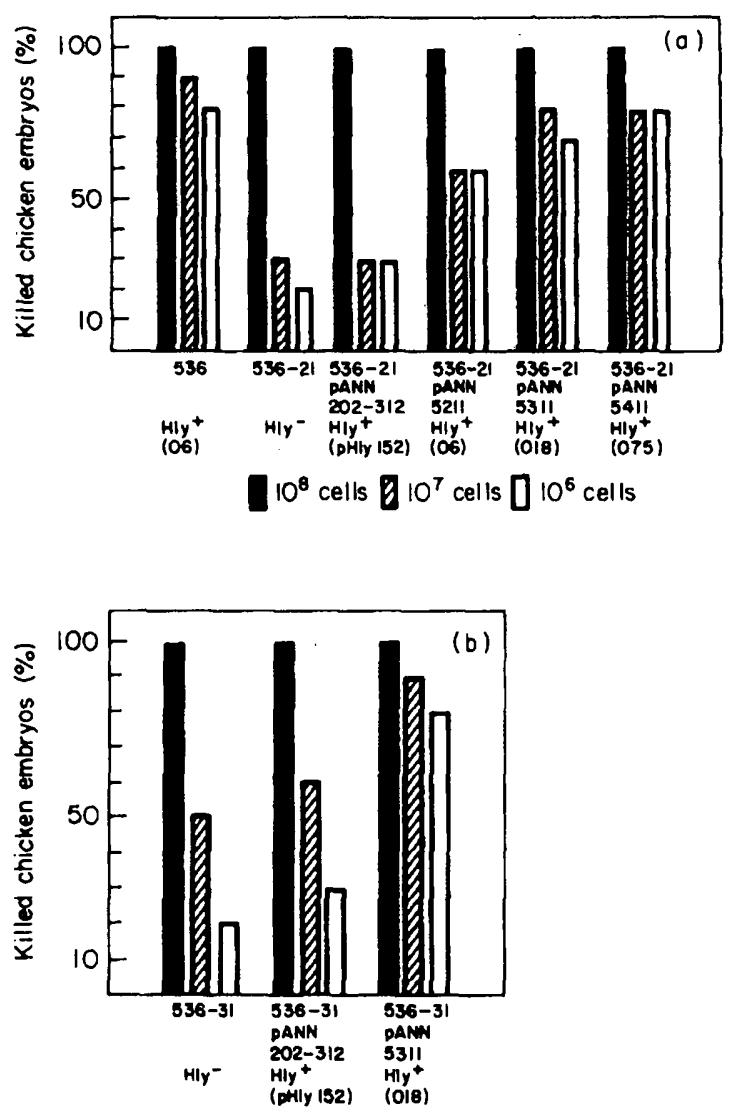

Fig. 2 (a) and (b). Influence of transformed cloned hly determinants on the lethality for chicken embryos of the E. colistrains 536-21 (Hly ${ }^{-}, \mathrm{Sfa}^{-}, \mathrm{Sre}^{-} ; 2 \mathrm{a}$ ) and 536-31 $\mathrm{HHly}^{-}, \mathrm{Sfa}^{+}, \mathrm{Sre}^{+} ; 2 \mathrm{~b}$ ). Ten chicken embryos were used per strain and inoculum.

\section{Chicken embryo assay}

In order to elucidate the influence of the $E$. coli hemolysin, S-fimbriae and serum resistance on the outcome of the infection, 10 days-old chicken embryos were infected with $1 \times 10^{6}$ to $1 \times 10^{8}$ bacteria. The number of dead embryos was recorded 48 hours after infection. $1 \times 10^{7}$ bacteria of the parental strain $E$. coli 536 killed $90 \%$ of the infected chicken embryos, whereas after injection of $1 \times 10^{6}$ bacteria $80 \%$ of the embryos died (see Fig. 2(a)). The lethality of the spontaneous mutant 536-21 was much lower. Following injection of $1 \times 10^{7}$ and $1 \times 10^{6}$ bacteria, only $30 \%$ and

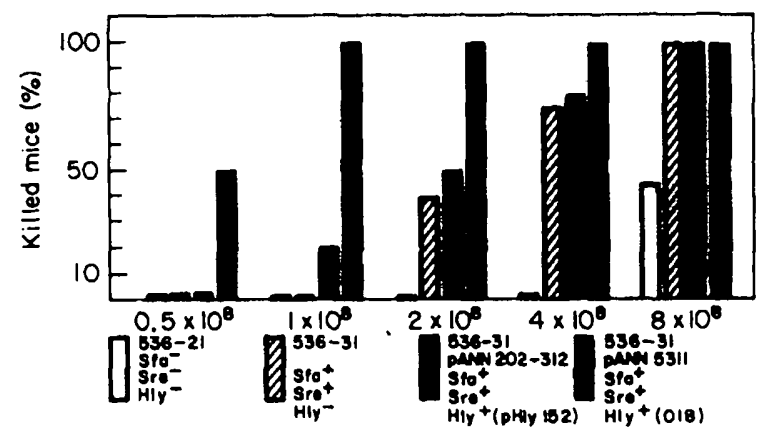

Fig. 3. Lethality for mice of the $\mathrm{Hly}^{-}, \mathrm{Sfa}^{+}, \mathrm{Sre}^{+}$strain 536-31 transformed with the recombinant $h l y^{+}$ plasmids pANN202-312 and pANN5311. Ten mice were used per strain and inoculum. 
$20 \%$, respectively, of the chicken embryos died. The restoration of S-fimbriae production and serum resistance in strain 536-31 had no significant influence on lethality (Fig. 2(b)). Transformation with the plasmid-encoded $h / y$ determinant did not increase the virulence in either of the $\mathrm{Hly}^{-}$strains. In contrast the introduction of the chromosomally encoded $h / y$ determinants increased the chicken embryo lethality of both $\mathrm{Hly}^{-}$strains to a level comparable to that of their $\mathrm{Hly}^{+}$parent. Thus only the cloned chromosomal hly determinants significantly contribute to toxicity in chicken embryos.
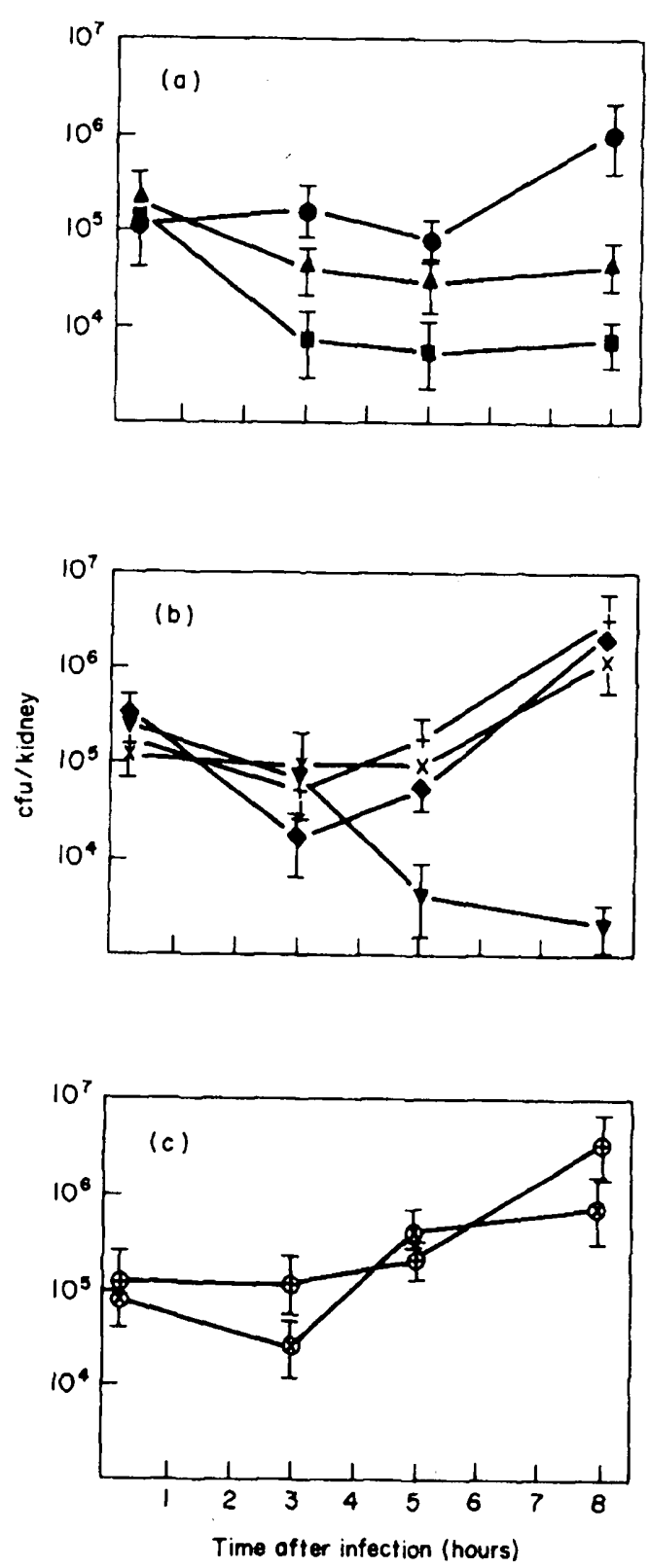

Fig. 4. Number of $E$. coli bacteria in mouse kidneys after i.v. injection of $2.5 \times 10^{8}$ cells of (a) strain

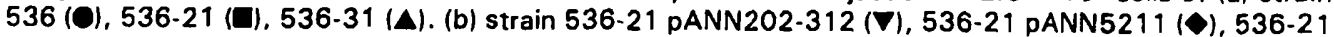
pANN5311 $(+), 536-21$ pANN5411 $(x)$ and $1 \times 10^{8}$ cell of $(c)$ strain 536-31 pANN202-312 (๑), 536-31 pANN5311 $(\otimes)$. Four mice were used per strain and time interval. Means and mean errors (ME) were calculated. 
Mouse lethality after i.p. infection

As described recently the chromosomally encoded 018 hly determinant increased the mouse virulence of the $\mathrm{Hly}^{-}$, non-fimbriated, serum-sensitive strain 536-21 after i.p. infection whereas the plasmid-encoded $h l y$ determinant had a very small effect. ${ }^{24}$ In order to test whether the S-fimbrial adhesin and the serum resistance factor had an influence on the virulence in this assay system we introduced both hly determinants into the S-fimbriated, serum-resistant Hly ${ }^{-}$strain 536-31.

As can be seen in Fig. 3 both S-fimbriae and serum resistance had a moderate effect in the assay. Strain 536-31 showed a 4-fold lower LD $_{50}$ value than strain 536-21. In addition the plasmid-encoded $h / y$ did increase the lethality of 536-31 to some extent but the 018-hly determinant had a much more noticable contribution to virulence. In contrast to the $\mathrm{Hly}^{-}$strains $536-21$ and 536-31 all the hemolytic strains including 536-21 pANN202-312 and 536-31 pANN202-312 (plasmid-encoded hly determinants) cause symptoms of hemoglobinuria indicating that hemolysin is produced in vivo.

Number of bacteria in the kidney after i.v. infection

Nearly $2.5 \times 10^{8} \mathrm{E}$. coli cells were injected intravenously into mice and the number of bacteria per kidney were measured after 15 min to 8 hours. Strain 536 shows a 10-fold increase in the numbers of bacteria per kidney during the first 8 hours after infection (Fig. 4(a)). The number of bacteria per spleen decreased by a factor of 10 (data not shown). Following these results strain $\mathbf{5 3 6}$ was termed as mouse nephrovirulent. ${ }^{32}$ Renal bacterial counts of strain 536-31 decreased within the time period of eight hours but infection of mice with that strain resulted in a higher number of bacteria per kidney than inoculation of 536-21 cells. Strains 536-21 and 536-31 were defined as non-nephrovirulent, although it is interesting to note that S-fimbriae and serum resistance had a small influence on renal bacterial counts.

The same was true for the plasmid-encoded $h l y$ determinant transformed in 536-21 (Fig. 4(b)). Surprisingly, in strain 536-31 the $h l y$ determinant from pHly 152 provokes an increase in renal bacterial counts (Fig. 4(c)). Introduction of the chromosomally encoded $h / y$ determinants cause an increase in the number of bacteria per kidney from $0.5-2 \times 10^{5}(15 \mathrm{~min})$ to $0.5-2 \times 10^{6}(8$ hours, for details see Fig. $4(\mathrm{~b})$, (c)). It seems that chromosomally encoded hemolysin is responsible for the manifestation of bacteria in the mouse kidney over a short period of time after infection. In all cases tested the number of bacteria per spleen decreased over a period of 8 hours. After 24 hours low bacterial counts $\left(10^{2}\right)$ were observed either in kidney or in spleen for all strains (data not shown). As already mentioned in the case of the mouse peritonitis model all $\mathrm{Hly}^{+}$strains result in the appearance of acute hemoglobinuria.

Table 2 Lung toxicity after i.n. infection of $1.5 \times 10^{8} \mathrm{Hly}^{+}$ and Hly- E. coli strains into mice

\begin{tabular}{|c|c|c|}
\hline Strain & Killed mice/infected mice & Clinical symptoms" \\
\hline $\begin{array}{l}536 \\
536-21 \\
536-31 \\
536-21 \text { pANN202-312 } \\
536-21 \text { pANN5211-06 } \\
536-21 \text { pANN5311-018 } \\
536-21 \text { pANN5411-075 } \\
536-31 \text { pANN202-312 } \\
536-31 \text { pANN5311-018 }\end{array}$ & $\begin{array}{l}8 / 10 \\
-110 \\
-/ 10 \\
-/ 10 \\
2 / 10 \\
2 / 10 \\
2 / 10 \\
-110 \\
7 / 10\end{array}$ & $\begin{array}{l}+ \\
- \\
- \\
- \\
+ \\
+ \\
+ \\
+\end{array}$ \\
\hline
\end{tabular}

-Crepitation and dyspnoea. 


\section{Mouse respiratory infection}

The uropathogenic isolate 536 was lethal after intranasal (i.n.) infection of $2.5 \times 10^{8}$ bacteria in mice. All mice infected exhibited clinical symptoms of a lung disease including crepitation and dyspnoea and $80 \%$ of the animals died (Table 2). Strains 536-21 and 536-31 were avirulent for mice which were symptom-free after i.n. infection. After transformation of the chromosomally encoded hly determinants into 536-21 crepitation and dyspnoea were observed but only $20 \%$ of the mice died. Only the strain 536-31 harbouring the 018 hemolysin determinant provoked the same virulence effect as the wild-type isolate (clinical symptoms and high lethality). Thus $\mathrm{S}$-fimbriae and serum resistance could contribute as co-factors to the action of hemolysin in this assay.

All the killed mice exhibited pathomorphological changed tissue cells in the lung including zones of severe hemorrhagic lesions.

\section{Subcutaneously induced mouse sepsis assay}

Nearly $5 \times 10^{4}$ bacteria were injected subcutaneously into mice. Agar was used as adjuvant to provoke a skin abscess. Because bacteria were able to multiply within the mouse body so that increasing numbers could be isolated from the blood and some internal organs during the first days post infectionem this assay fulfills the criteria of a real septicemic infection ${ }^{\mathbf{3 2}}$. The parental strain $\mathbf{5 3 6}$ was isolated in relatively high numbers from the liver of mice during the first days after infection $\left(2-3 \times 10^{6}\right.$ bacteria, for details see Fig. 5), whereas the number of bacteria recovered following infection by 536-21 dropped dramatically. The introduction of chromosomally encoded hly determinants into 536-21 enhanced somewhat the ability of the strains to multiply within the mice. In addition strain 536-31 exhibited increasing numbers of bacterial counts in the liver. Thus in this assay the $\mathrm{Hly}^{-}$strain that had S-fimbriae and serum resistance was as virulent as the $\mathrm{Hly}^{+}$parent. The introduction of hemolysin had no further effect on the virulence of 536-31.

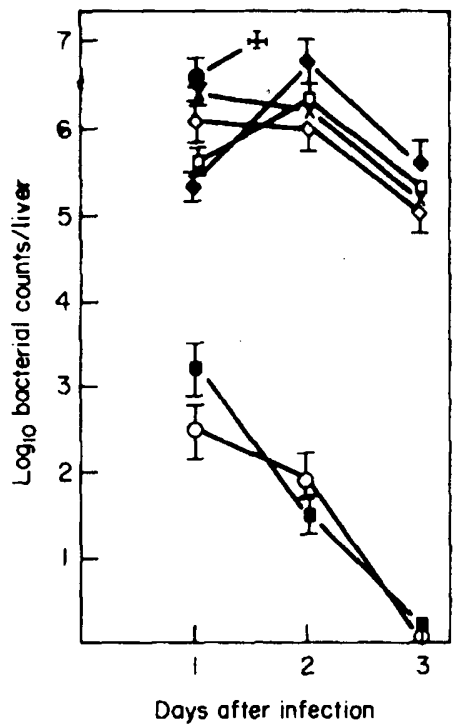

Fig. 5. Numbers of $E$. coli bacteria per mouse liver after mixed s.c. infection of $5 \times 10^{4}$ cells with $0.5 \mathrm{ml}$ tryptose agar. Strain 536 (O), 536-21 (O), 536-21 pANN202-312 (D), 536-21 pANN5311 (口), 536-31 $(\times), 536-31$ pANN202-312 ( $), 536-31$ pANN5311(১). 5 mice were used per strain and time interval. Means and means errors (ME) were calculated. 
Table 3 Summary of the in vivo results with strain $536(06: \mathrm{K} 15: \mathrm{H} 31)$ and its derivatives

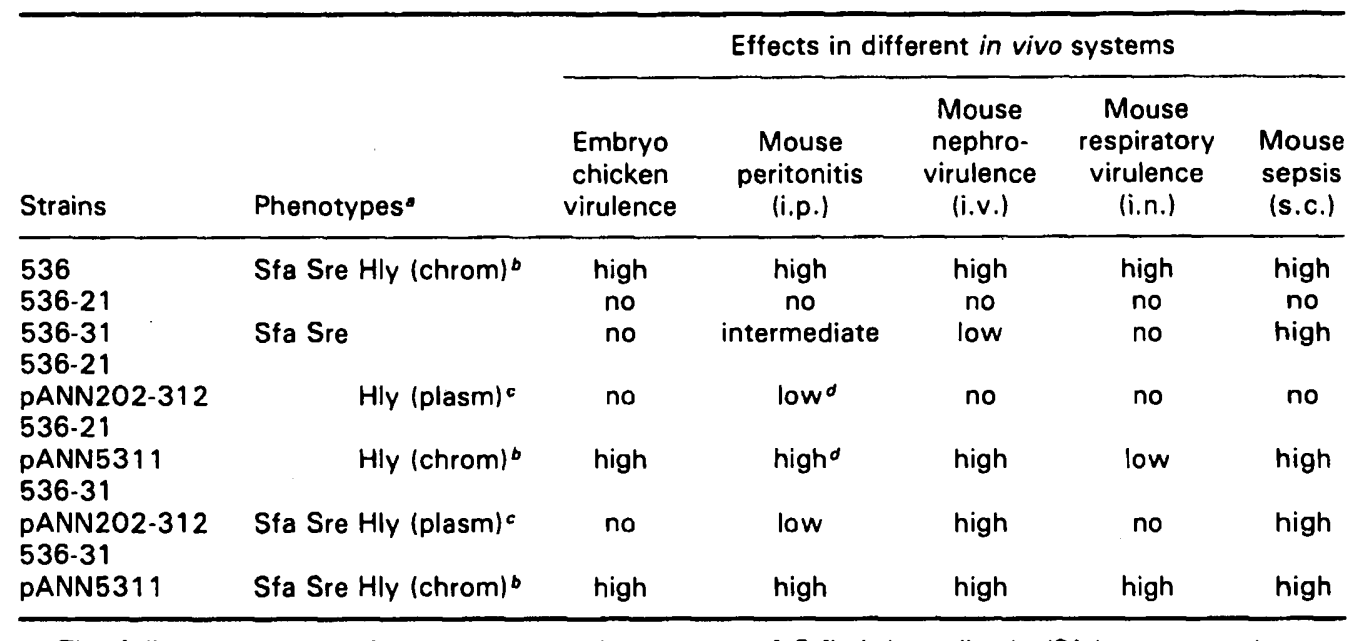

- The following characteristics were tested: presence of S-fimbriae adhesin (Sfa), serum resistance (Sre) and hemolysin production (Hly).

'Chromosomally encoded hemolysin of serogroup 06 (536) or 018 (pANN5311). The recombinant DNA pANN5311 transformed into 536-21 has nearly the same effects on virulence as the hly ${ }^{+}$plasmids PANN5211 (06) and pANN5411 (075).

cPlasmid encoded hemolysin from the Hly ${ }^{+}$plasmid pHly 152.

Data from ref. 24.

\section{Discussion and conclusion}

Using five different animal models we have provided evidence that hemolysin contributes to virulence in extraintestinal infections caused by Escherichia coli. Four different hemolysin determinants cloned and subcloned in the same way were transformed into two different host strains. As summarized in Table 3 in all infection models, the chromosomally encoded hly determinants had a greater effect on virulence than the determinant from the plasmid pHly152. S-fimbriae and serum resistance had a definitive effect in the mouse sepsis assay even in the absence of hemolysin and to a smaller extent, in the mouse peritonitis system. A cooperative effect of S-fimbriae and serum resistance together with hemolysin was detected in the mouse respiratory model. We will first compare the different animal models used and then we will discuss the role of the bacterial virulence factors in the infectious process.

\section{Chicken embryo assay}

In this in vivo assay immune response and the endogenous microbial flora are not subject to variation and do not influence the outcome of the test. Multiplication of bacteria does not play a decisive role in this assay and it has been asserted that this test closely reflects the toxic potency of the material tested. ${ }^{33 .}{ }^{34}$ Hemolysin was the only factor which influenced the virulence of the strains. The fact that $E$. coli K-12 strains with or without hemolysin were non-viru:ant in all cases tested ${ }^{35,36}$ (Hacker, unpublished results) however demonstrates that LPS is absolutely necessary for chicken embryo virulence. In comparison to the results of other investigators according to which the $E$. coli $L D_{50}$ range from $10^{1}$ to $10^{911,22,35}$ strain 536 with an $L D_{50}$ of $10^{7}$ was of intermediate virulence. 
Mouse lethality after i.p. infection

As described for the chicken embryo assay, strain 536 was also of intermediate virulence in the mouse peritonitis system. ${ }^{24}$ Immediately after i.p. injection bacteria had moved to the blood vessels and could be isolated from different organs like the spleen and the liver. But while sepsis- and meningitis-E. coli isolates like 018:K 1 strains are able to overcome the host defense barrier and begin to multiply even after infection by only $4 \times 10^{5}$ bacteria, ${ }^{37}$ decreasing numbers of 536 bacteria were isolated from the spleens beginning with the first hours after injection. Thus introduction of 018:K1 strains and uropathogenic strains like 536 results in different modes of infection.

In the 536 infection, death of mice was not recorded until 10-20 hours after infection, i.e. when the number of bacteria in the mouse was in the decline. It has been suggested by several authors ${ }^{24,25}$ that this may be the minimal period of time within which enough hemolysin is produced to show its toxic potential. In all cases of infection with $\mathrm{Hly}^{+}$strains hemoglobinuria was observed which proves that hemolysin was really produced in vivo. Because this symptom was also observed after infection with non-virulent $\mathrm{Hly}^{+}$-strains (like pANN202-312/536-21) it seems that lysis of erthrocytes is not the main pathogenic effect of $E$. coli hemolysin.

\section{Mouse nephrovirulence after i.v. infection}

This animal model resembles the mouse peritonitis assay and the chicken embryo system because relatively high numbers of bacteria $\left(1-2 \times 10^{8}\right)$ were used for infection, a small multiplication rate of bacteria was observed and no persistence of bacterial cells for longer than $\mathbf{2 4}$ hours was recorded. Moreover, infection in both cases involved introduction of the bacteria into the blood stream. In the nephrovirulence mouse assay bacteria were given i.v. and renal bacterial counts were estimated $15 \mathrm{~min}$ to 8 hours after infection. While spleen counts decreased continuously, renal counts increased when the strains were hemolytic (with the exception of pANN202-312/536-21, see Table 3). The differences between the serumresistant, S-fimbriae positive strain 536-31 and the serum sensitive, S-fimbriae negative strain $536-21$ seem to reflect the different $L_{50}$ values. In agreement with previously used terminology 20.32 we define $536 \mathrm{Hly}^{+}$strains as group II clones (high $L D_{50}$ values, high renal counts) rather than group III (low $L_{50}$ values, high renal counts). The former are mostly uropathogenic isolates whereas the latter very often belong to $E$. coli blood strains. ${ }^{20}$ In general this animal model seems to be rather sensitive to the presence or absence of hemolysin because in the case of 536-31 host strain even the plasmid encoded hemolysin had an effect but serum resistance and S-fimbriae seem to be necessary as cooperative agents.

\section{Mouse respiratory infection}

In this model $E$. coli strains were compared in terms of their ability to cause a severe infection of the lung after intranasal infection of mice with nearly $1 \times 10^{8}$ bacteria. Only those strains which code for serum resistance and S-fimbriae after introduction of chromosomally encoded hemolysin provoked a fatal lung oedema disease. Death of mice followed rapidly the development of clinical symptoms such as crepitation and dyspnoe. Hemorrhagic oedema were present in the lung, possibly as a result of intravasal hemolysis. Such pathomorphological symptoms were also observed after i.v. infection of mice ${ }^{38}$ and in rabbits following intradermal injection of serum resistant $\mathrm{Hly}^{+}$bacteria. ${ }^{39}$ It appears therefore that this infection is quite different from a slowly progressing interstitial pneumonia developing in mice surviving the acute oedemic phase. 
The mouse lung oedema assay was originally developed to characterize swine pathogenic 0139 E. coli strains which cause severe diarrhoeal disease and hemorrhagic oedema in the gut. ${ }^{40,41}$ Because all of the 0139 strains isolated were $\mathrm{Hly}^{+42}$ it was suggested that hemolysin should be responsible for development of oedema in this intestinal infection. Although our results clearly confirm this assumption a direct contribution of hemolysin to swine disease has to be demonstrated in the future by the use of $\mathrm{Hly}^{+}$and $\mathrm{Hly}^{-}$isogenic 0139 strain pairs.

Systemic infection of mice after s.c. injection

In contrast to the other in vivo models discussed only low numbers of bacteria are required to produce a progressing systemic disease ${ }^{32 \mathrm{a}}$. Agar, as conditioning agent, is necessary. Bacteria do not only produce a local abscess at the site of injection but spread to distant organs, where they can be isolated in very high numbers. A prerequisite for bacterial survival and multiplication is, however, the ability of the bacterial cells to express S-fimbriae and to be serum resistant. In addition, chromosomally-encoded hemolysis is able independently to restore virulence in this particular model. The contribution of S-fimbriae to pathogenicity in another septicemic mouse system was recently demonstrated for 018:K1 strains. ${ }^{37}$

Role of S-fimbriae and serum resistance in infection

Strains 536-31 and 536-21 differ in the presence or absence of serum resistance (Sre) and S-fimbriae (Sfa). As indicated in Table 3 both factors contribute to virulence in the mouse sepsis assay. An adhesion of $E$. coli by $S$-fimbriae to mouse cells has not been demonstrated yet in a suitable in vitro assay but the presence of such antigens leads to an advantage in two different mouse systems as well as in a rat pyelonephritis model29. 37 (Marre et al., submitted).

Serum resistance is a prerequisite for long term survival of the strains in models where the complement system is activated. In the mouse peritonitis model and the respiratory assay both $\mathrm{S}$-fimbriae and serum resistance act in cooperation with hemolysin; such cooperative effects were also observed in in vitro assays where Sfimbriae, serum resistance and hemolysin together stimulate the release of some mediators of inflammation. ${ }^{44}$ The question whether Sre-factor or S-fimbriae or both are responsible for the observed effects is one that will be answered in the near future by the use of a cloned sfa-determinant. ${ }^{7}$

\section{Role of hemolysin in infection}

It has been shown that virulence of bacteria can be modulated in all five in vivo systems by the expression of hly genes. The hemolysin determinants were introduced into the $\mathrm{Hly}^{-}$host strains by transformation of recombinant DNAs and there should be no doubt that the in vivo effects observed results from the action of hemolysin itself. The hemoglobinuria which was observed after infection of mice with $\mathrm{Hly}^{+}$ strains indicates that hemolysin indeed was produced in the animal. The fact that such hemoglobinuria was also observed following infection by non-virulent $\mathrm{Hly}^{+}$strains indicates that lysis of erythrocytes and a subsequent uptake of free iron ${ }^{25.45}$ could not be the main mechanism in the mode of action of $E$. coli hemolysin. Indeed indications exist that a cytolytic action of hemolysin on renal cells and leukocytes, triggering an inflammatory response, may be involved 18.19.43.44 (Lund, unpublished observations). The in vivo data presented here also suggest an injury of animal tissues by the action of hemolysin.

Such a pathogenic effect of hemolysin was observed as early as 8 hours after infection in the case of the mouse nephrovirulence model and after similar lengths of 
time in other in vivo systems. But this action of hemolysin very early in infection greatly depends on the kind of the in vivo model used. One should keep in mind that these models are more or less artificial short term assays representing only one aspect of the complex picture of a urinary tract infection. In human UTI hemolysin would be expected to act after establishment of the bacteria in the urinary tract, i.e. rather late in the infectious process.

\section{Differences between various hemolysin determinants}

In this study we also present evidence that the plasmid-encoded hly determinant of pHly 152 does not increase the pathogenicity of the host cell as much as the chromosomally encoded determinants (Table 3 ). Differences in the $5^{\prime}$ upstreams sequences of $h / y C$ including the promoter region (see Fig. 1) could be one reason for these differences as suggested by Welch \& Falkow. ${ }^{46}$ This region was otherwise held constant in all the recombinant $h l y^{+}$DNAs used here because it was derived from the plasmid pHly 152. Thus the observed differences in virulence could only be explained on the basis of the differences in the structural gene for hemolysin (hlyA) and/or the genes $h / y B$ and $h / y D$, involved in the secretion of hemolysin.

A comparison of the predicted amino acid sequences of the gene products on the basis of the nucleotide sequences of a chromosomal and a plasmid encoded hly determinant ${ }^{17,17 \mathrm{a}}$ indeed shows interesting differences between the corresponding proteins of pHly 152 and the 04 strain J96. First, amino acid exchanges in HlyA occur preferentially in the $\mathrm{N}$-terminal and $\mathrm{C}$-terminal parts of the protein. Similar exchanges have also been observed with the 018 and 075 hemolysin used here ${ }^{17}$. Second, the observed amino acid substitutions in HlyB and HlyD could be important for virulence and there is indeed some evidence that the interaction between these proteins and HlyA could effect the virulence level of the strains (Wagner \& Goebel, unpublished results).

In addition one cannot exclude the possibility that the flanking regions or DNA sequences to the left of the IS2 element, ${ }^{16}$ which is located upstream of $h l y C$ have an influence on virulence. Recent in vivo data comparing the virulence effects of the Hindlli/Sall hly fragment of pHly152 (pANN202-312) and the Sall/Sall fragment harboring another $3 \mathrm{~kb}$ DNA upstream of IS2 confirm this assumption (Hacker $e t$ al., in preparation).

\section{Materials and methods}

\section{E. coli strains}

The E. coli strain 536 was obtained from the Institut für Hygiene und Mikrobiologie, Würzburg. ${ }^{28}$ The mutant strains 536-21 and 536-31 were described elsewhere ${ }^{15.28}$ (see above). All three strains belong to the serotype 06:K15:H31 and they are resistant to streptomycin. The strains were further characterized with respect to adhesin formation, serum resistance and hemolysin production (see Table 1). 536-21 and 536-31 were used as recipients in transformation experiments.

\section{Recombinant DNAs}

The recombinant hemolysin $\left(h / y^{+}\right)$plasmids used (pANN202-312, pANN5211-06; pANN5311-018, pANN5411-075) contain BamHI-Sall fragments carrying the genes $h / y A, h l y B$ and $h l y D$ of various chromosomal (strains 536-06, 764-018, 341-07531) and plasmid-(pHly 152 $\left.{ }^{30}\right)$ encoded $h l y$ determinants cloned into pANN202. pANN2O2 is pACYC184 bearing hlyC of the plasmid pHly 152 (Table 1 and Fig. 1). pANN801 is a cosmid coding for the S-fimbriae adhesin. ${ }^{7}$ 
Isolation of plasmid DNA

Preparative DNA isolation was achieved as described. ${ }^{47}$ Plasmid DNA from transformants carrying recombinant DNA was screened by the clear lysate procedure. ${ }^{48}$

\section{Transformation}

The wild-type strains 536-21 and 536-31 were transformed with hly recombinant plasmids by a modified $\mathrm{CaCl}_{2}$ procedure. ${ }^{49}$ These strains were grown in Luria(L) broth.

\section{Characterization of transformants, cultures used for in vivo tests and} strains reisolated from animals

Transformed strains and those isolated from organs of dead or surviving animals were checked for the presence of covalently closed circular DNA and markers of the recombinant DNA (chloramphenicol resistance, hemolysin production). All the 536-21 and 536-31 transformants and derivatives were further tested for chromosomally encoded streptomycin resistance. Production of K15-and O6-antigens were checked with antisera raised against 06-and K15-standard strains. The antigen titers were estimated in microtiter plates as described earlier. ${ }^{50}$ Ampicillin resistance was determined for strain 536-31 and its transformants.

Formation of S-fimbriae adhesin ( $\mathrm{Sfa}$ ) was determined by agglutination of human and bovine erythrocytes and S-specific antiserum. Hemagglutination was resistant to the presence of $1 \%$ mannose and was abolished after treatment of erythrocytes with neuraminidase. ${ }^{7}$ Serum resistance (Sre) of the strains was assayed after growing ca. $2 \times 10^{5}$ bacterial cells in $90 \%$ human serum for 3 hours. ${ }^{1.51}$ Hemolysin production was detected on blood agar plates and confirmed in a liquid assay. ${ }^{14}$ Before using the strains in animal tests they were grown in $L$ broth in the presence of chloramphenicol. After washing in phosphate buffered saline (PBS) and before use suitable dilutions of the cultures were plated in blood agar. With the exception of some single colonies no segregants (non-hemolytic, chloramphenicol sensitive) were detectable. In strains reisolated from animals more than $90 \%$ of the cells retained their extrachromosomal $h l y^{+}$DNAs.

\section{Chicken embryo virulence test}

The lethality of bacteria to chicken embryos was assessed by a modification of the test described by Powell \& Finkelstein. ${ }^{33}$ In preliminary experiments it was estimated that the 10 day old embryos were maximally susceptible. The embryonated hen eggs were free of Salmonella pullorium and were incubated at $37^{\circ} \mathrm{C}$ under sterile conditions. Bacteria were grown overnight at $37^{\circ} \mathrm{C}$ in $\mathrm{L}$ broth under antibiotic pressure and were suspended in sterile PBS. As determined earlier the critical inoculum for strain 536 and its derivatives was $10^{6}$ to $10^{8}$ bacteria. After infection of $10^{5}$ cells all chicken embryos survived. Thus $1 \times 10^{8}, 1 \times 10^{7}$ and $1 \times 10^{6}$ bacteria (in $0.1 \mathrm{ml} \mathrm{PBS}$ ) were introduced into the allantoic cavity of 10 day old chicken embryos (Institut für Virologie, Univ. Würzburg). In all tests 10 chicken embryos were used per strain and inoculum. Death was recorded 48 hours after infection. All experiments were done three times.

Assay for lethality in adult mice after i.p. injection

The lethality of bacteria for mice was assessed as described earlier. ${ }^{24}$ Cells of overnight cultures (grown in L broth) were harvest, washed in PBS and resuspended to ca. $10^{9}$ viable cells $/ \mathrm{mel}$. It was obvious from earlier studies that the $L_{50}$ strain 536 and its derivatives range from $0.5-8 \times 10^{8}$. Thus $5 \times 10^{7}$ to $8 \times 10^{8} \mathrm{E}$. coli cells 
resuspended in $0.2 \mathrm{ml}$ PBS were injected into the peritoneal cavity of 8 week old $20 \mathrm{~g}$ female NMRI mice (Zentralinstitut für Versuchstiere, Hannover). The animals were held in a specific pathogen free (SPF) status. The number of mice killed after $24 \mathrm{~h}$ was recorded. Ten mice were used per strain and inoculum. All experiments were done three times. Clinical signs, survival times and macroscopic lesions of mice including hemoglobinuria were recorded.

Assay for virulence in adult mice after i.v. injection

The virulence test was done in accordance to Van den Bosch et al. ${ }^{20}$ Briefly, bacteria were grown in L broth till late log phase, centrifuged and washed with PBS. Nearly $2.5 \times 10^{8} \log$ phase bacterial cells $\left(1.0 \times-10^{8}\right.$ for $536-31 \mathrm{Hly}^{+}$transformants $)$were injected intravenously into $20 \mathrm{~g}$ CFLP/LATI female mice (GÖDÖLLÖ. Hungary) or into $20 \mathrm{~g}$ female NMRI mice. The numbers of bacteria per kidney were measured after $15 \mathrm{~min}, 3,5,8$ and 24 hours. In order to avoid interference with spleen counts only the right kidney was used for estimation. Four mice were used per strain and time interval. All experiments were done twice.

\section{Mouse respiratory infection}

CFLP/LATI female mice (10-12 g) were infected intranasally under superficial ether anaesthesia with $0.05 \mathrm{ml}$ overnight $L$ broth culture, containing nearly $3 \times 10^{9}$ bacteria/ml. The death rate was recorded $24 \mathrm{~h}$ after infection. During infection the clinical symptoms of a lung disease were observed. After death of mice the lungs were removed and macroscopical visible pathomorphological changes like occurrence of hemorrhagic lung oedema were recorded. In negative cases the mice survived or died only after a few days showing an interstitial pneumonia. Ten mice were used per strain and all experiments were done twice.

\section{Mouse sepsis assay}

$0.3 \mathrm{ml}$ PBS containing nearly $5 \times 10^{4} \mathrm{E}$. coli cells were mixed with $0.5 \mathrm{ml}$ liquified $\left(45^{\circ} \mathrm{C}\right)$ tryptose-agar $(1.5 \%)$. The suspension was injected subcutaneously in the back of nice. After 1, 2, and 3 days the livers of dead mice were removed and homogenized and colony forming bacteria were counted. Five mice were used per strain and time interval. The experiments were done twice.

\section{Statistics}

The $L D_{50}$ values were calculated by the method of Kärber. ${ }^{52}$ For further statistical evaluations the publication of Cavali-Sforza ${ }^{53}$ was used.

The authors wish to thank $H$. Jungwirth (Würzburg) for help and advice, Sophia Kathariou (Würzburg) for critical reading of the manuscript, and Rose Lajko (Pecs) and Heike Düvel (Würzburg) for technical assistance. This work was supported by the Deutsche Forschungsgemeinschaft (Go 168/1-3) and the Scientific Research Council of the Hungarian Ministry of Health (3-10-0305-03-1/K).

\section{References}

1. Hughes C, Hacker $H$, Roberts A, Goebel W. Hemolysin as a virulence marker in symptomatic and asymptomatic urinary tract infections caused by Escherichia coli. Infect Immun 1983; 39: 546-51.

2. Väisänen-Rhen V, Elo J, Väisänen E, Siitonen A, Ørskov F, Svenson SB, Mäkelä PH, Korhonen TK. $P$ fimbriated clones among uropathogenic Escherichia coli strains. Infect Immun 1984; 43: $149-55$.

3. Korhonen TK, Valtonen MV, Parkkinen J. Väisänen-Rhen V, Finne J, Ørskov I, Svenson SB, Mäkelä $\mathrm{PH}$. Serotype, hemolysin production, and receptor recognition of Escherichia coli strains associated with neonatal spesis and meningitis. Infect Immun 1985; 48: 486-91. 
4. Achtman M, Pluschke G. A clonal analysis of descent and virulence among selected Escherichia coli bacteria. Ann Rev Microbiol 1986; in press.

5. Källenius G, Möllby R, Svenson SB, Winberg J, Lundbad A, Svensson $S$. The $p^{k}$ antigen as receptor of pyelonephritis E. coli. FEMS Microbiol Lett 1980; 7: 297-301.

6. Korhonen TK, Väisänen-Rhen V, Rhen M, Pere A, Parkkinen J, Finne J. Escherichia coli fimbriae recognizing sialyl galactosides. J Bacteriol 1984; 159: 762-6.

7. Hacker J, Schmidt G, Hughes C, Knapp S, Marget M, Goebel W. Cloning and characterization of genes involved in production of mannose-resistant neuraminidase-susceptible (X) fimbriae from a uropathogenic 06:K 15:H31 Escherichia coli strain. Infect Immun 1985; 47: 434-40.

8. Westphal $O$, Jann K, Himmelspach $K$. Chemistry and immunochemistry of bacterial lipopolysaccharides as cell wall antigens and endotoxins. Prog Allergy 1983; 33: 9-39.

9. Timmis KN, Boulnois GJ, Bitter-Suermann D, Cabello FC. Surface components of Escherichia coli that mediate resistance to the bacterial activities of serum and phagocytes. Curr Top Microbiol Immun 1985; 118: 197-218.

10. Hacker J, Hughes H. Genetics of Escherichia coli hemolysin. Curr Top Microbiol Immunol 1985; 118 : 139-62.

11. Minshew BH, Jorgenson J, Counts GW, Falkow S. Association of hemolysin production hemagglutination of human erythrocytes, and virulence for chicken embryos at extraintestinal Escherichia coli isolates. Infect Immun 1978; 20: 50-4.

12. Müller $D$, Hughes $C$, Goebel $W$. Relationship between plasmid and chromosomal hemolysin determinants of Escherichia coli. J Bacteriol 1983; 163: 846-51.

13. Noegel A, Rdest U, Goebel W. Determination of the functions of hemolysin plasmid pHly 152 of Escherichia coli. J Bacteriol 1981; 145: 233-47.

14. Wagner W, Vogel M, Goebel W. Transport of hemolysin across the outer membrane of Escherichia coli requires two functions. J. Bacteriol 1983; 154: 200-10.

15. Knapp S, Hacker J, Then I, Müller D, Goebel W. Multiple copies of hemolysin genes and associated sequences in the chromosome of uropathogenic Escherichia coli strains. J. Bacteriol 1984; 159: 1027-33.

16. Knapp S, Then I, Wels W, Michel G, Tschäpe H, Hacker J, Goebel W. Analysis of the flanking regions from different haemolysin determinants of Escherichia coli. Mol Gen Genet 1985; 200: 385-92.

17. Felmlee T, Pellett S, Welch RA. Nucleotide sequence of an Escherichia coli chromosomal hemolysin. J Bacteriol 1985; 163: 94-105.

17a. Hess J, Wels W, Vogel M, Goebel W. Nucleotide sequence of a plasmid-encoded hemolysin determinant and its comparison with a corresponding chromosomal hemolysin sequence. FEMS Microbiol Lett 1986; 34: 1-11.

18. Cavalieri SJ, Snyder IS. Effect of Escherichia coli alpha-hemolysin on human peripheral leukocyte viability in vitro. Infect Immun 1982; 36: 455-61.

19. De Pauw AP, Gill WB, Fried FA. Etiology of pyelonephritis: renal lysosome disruption by hemolytic Escherichia coli Invest Urol 1971; 9: 230-3.

20. Van den Bosch JF, Postma P, de Graaff J, MacLaren DM. Hemolysis by urinary Escherichia coli and virulence in mice. $J$ Med Microbiol 1981; 14: 321-31.

21. Waalwijk C, Van den Bosch JF, MacLaren DM, De Graaff J. Hemolysin plasmid coding for the virulence of a nephropathogenic Escherichia coli strain. Infect Immun 1982; 35: 32-7.

22. Hull SJ, Hull RA, Minshew BH, Falkow S. Genetics of hemolysin of Escherichia coli. J Bacteriol 1982; 151: 1006-12.

23. Welch RA, Dellinger EP, Minshew B, Falkow S. Haemolysin contributes to virulence of extraintestinal E. coli infections. Nature (London) 1981; 294: 665-7.

24. Hacker J, Hughes $C$, Hof $H$, Goebel W. Cloned hemolysin genes from Escherichia coli that cause urinary tract infection determine different levels of toxicity in mice. Infect Immun 1983; 42: 57-63.

25. Smith HW. Huggins MB. The toxic role on alpha-haemolysin in the pathogenesis of experimental Escherichia coli infection in mice. J Gen Microbiol 1985; 131: 395-403.

26. Losse H, Asscher AW, Lison AE, Andriole VT (eds). Pyelonephritis, vol. V.G. Stuttgart. ThiemeVerlag, 1984; 000-000.

27. Mäkelä PH. Functional epidemiology of bacterial meningitis. Infection 1984; 12 (Suppl.): 529-32.

28. Hacker J, Knapp S, Goebel W. Spontaneous deletions and flanking regions of the chromosomally inherited hemolysin determinant of an Escherichia coli 06 strain. J Bacteriol 1983; 154: 1145-52.

29. Hacker J, Jarchau T, Knapp S, Marre R, Schmidt G, Schmoll T, Goebel W. Genetic and in vivo studies with $S$ fimbriae antigens and related virulence determinants of extraintestinal $E$. coli strains. In: Lark D, Normak S, Wolf-Watz H, Uhlin BE, eds. Molecular Biology of Microbial Pathognecity. London: Academic Press, 1986; (in press).

30. Goebel W, Hedgpeth J. Cloning and functional characterization of the plasmid-encoded hemolysin determinant of Escherichia coli. J Bacteriol 1982; 151: 1290-8.

31. Berger $H$, Hacker J, Juarez A, Hughes C, Goebel W. Cloning of the chromosomal determinants encoding hemolysin production and mannose-resistant hemagglutination in Escherichia coli. $J$ Bacteriol 1982; 152: 1241-7.

32. Van den Bosch JF, Emödy L, Ketyi J. Virulence of haemolytic strains of Escherichia coli in various animal models. FEMS Microbiol Lett 1982; 13: 427-30. 
32a. Hof H, Christen A, Hacker J. Comparative therapeutic activities of ciprofloxacin, ampicillin, ceftriaxone and cotrimoxazole in a new model of experimental infection with Escherichia coli. Infection 1986; in press.

33. Powell CJ, Finkelstein RA. Virulence of Escherichia coli strains for chick embryos. J Bacteriol 1966; 91: 1410-7.

34. De Azavedo JCS, Lucken RN, Arbuthnott JP. Effect of toxic shock syndrome toxin 1 on chicken embryos. Infect Immun 1985; 47: 710-2.

35. Minshew BH, Jorgenson J, Swanstrum M, Grootes-Reuvecamp GA, Falkow S. Some characteristics of Escherichia coli strains isolated from extraintestinal infections of humans. J Infect Dis 1978; 137: 648-54.

36. Goebel W, Hacker J, Hughes C, Knapp S, Hof H, Müller D, Juarez A, Kreft J. Gene cloning and pathogenicity. In: Arber W, Illmensee K, Peacock WJ, Starlinger P, eds. Genetic manipulation impact on man and society. London: ISCU Press, 1984; $29-42$.

37. Nowicki B, Vuopio-Varkila J, Viljanen P, Korhonen TK, Mäkelä PH. Fimbrial phase variation and systemic $E$. coli infection studies in the mouse peritonitis model. Microbial Pathogenesis 1986; 1 : (in press).

38. Smith HW. The haemolysins of Escherichia coli. J Pathol Bacteriol 1963; 85: 197-211.

39. Issekutz AC, Ripley M, Rochon Y, Pi-Jimenez E, Wright B. A role for hemolysin in Escherichia coliinduced inflammation in granulocytopenic rabbits. J Infect Dis 1984; 150: 925-34.

40. Ketyi J, Emödy L. Kontrohr T, Vertenyi A, Pasca S, Avdeeva RA, Safonova NV, Golutova NK. Mouse lung oedema caused by a toxic substance of Escherichia coli strains. Acta Microbiol Acad Sci Hung 1978; 25: 307-17.

41. Emödy L, Pal T, Safonova NV, Kuch B, Golutova NK. The alpha haemolysin as an additive virulence factor in Escherichia coli. Acta Microbiol Acad Sci Hung 1980; 27 : 333-42.

42. Lecce JG, Balsbaugh RK, Clare DA, King MW. Rotavirus and hemolytic enteropathogenic Escherichia coli in waening diarrhea of pigs. J Clin Microbiol 1982; 16: 715-23.

43. Gadeberg OV, Ørskov I. In vitro cytotoxic effect of $\alpha$-hemolytic Escherichia coli on human blood granulocytes. Infect Immun 1984; 45: 255-60.

44. Scheffer J, König W, Hacker J, Goebel W. Bacterial adherence and hemolysin production from Escherichia coli induces histamine and leukotriene release from various cells. Infect Immun 1985; 50: $271-78$

45. Linggood MA, Ingram PL. The role of alpha haemolysin in the virulence of Escherichia coli for mice. J Med Microbiol 1982; 15: 23-30.

46. Welch RA, Falkow S. Characterization of Escherichia coli hemolysins conferring quantitative differences in virulence. Infect Immun 1984; 43: 156-60.

47. Grinstedt J, Bennett PM, Higginson S. Richmond MH. Regional preference of insertion of In 501 and Tn 802 into RP1 and its derivatives. Mol Gen Genet 1978; 166: 313-20.

48. Birnboim HC, Doly J. A rapid alkaline extraction procedure for screening recombinant plasmid DNA. Nucl Acid Res 1979; 7: 1513-23.

49. Lederberg EM, Cohen SN. Transformation of Salmonella typhimurium by plasmid deoxyribonucleic acid. J Bacteriol 1974; 119: 1072-4.

50. Hacker J, Schröter G. Schrettenbrunner A, Hughes C, Goebel W. Hemolytic Escherichia coli strains in the human flora as potential urinary pathogens. Zbl Bakt Hyg I Abt Orig 1983; A 254: 370-8.

51. Taylor PW, Hughes C. Plasmid carriage and the serum sensitivity of enterobacteria. Infect Immun 1978; $22: 10-17$.

52. Kärber G. Beitrag zur kollektiven Behandlung pharmakologischer Reihenversuche. Arch Exp Path Pharamkol 1931; 162: 480-3.

53. Cavalli-Sforza L. Biometrie. Grundzüge biologisch-medizinischer Statistik. Jena: Fischer-Verlag, 1969. 